\title{
New applications of the acridine orange fluorescence staining method: Screening for circulating tumor cells
}

\author{
MIN LIU ${ }^{1}$, RUIZHE LI ${ }^{1}$, YANG TANG ${ }^{2}$, JIWU CHANG ${ }^{2}$, RONG HAN ${ }^{2}$, \\ SHUMIN ZHANG ${ }^{2}$, NING JIANG ${ }^{2}$ and FULING MA ${ }^{2}$ \\ ${ }^{1}$ Tianjin Institute of Urology, The Second Hospital of Tianjin Medical University; ${ }^{2}$ Department of Urology, \\ Tianjin Institute of Urology, The Second Hospital of Tianjin Medical University, Tianjin 300211, P.R. China
}

Received July 21, 2015; Accepted November 24, 2016

DOI: $10.3892 / 01.2017 .5724$

\begin{abstract}
The aim of the present study was to explore use of the acridine orange fluorescence (AO-F) staining method for screening of circulating tumor cells (CTCs) in renal cell carcinoma (RCC) patients. The AO-F positive staining rate of live and dead tumor cells was calculated. The positive staining rate in the live group was $93.4 \pm 3.0 \%$, while the dead group failed to emit specific fluorescence. A known number of tumor cells were added to peripheral blood, and the detection sensitivity of the four groups $(50,100,200$ and 500 cells/tube) was $10.2 \pm 3.8$, $9.2 \pm 2.3,10.8 \pm 2.6$ and $10.5 \pm 1.9 \%$, respectively. The average detection sensitivity of the four groups was $10.16 \pm 2.73 \%$. There was a positive correlation between the number of cells that was positively stained with AO-F and the total number cells in the system $\left(\chi^{2}=0.959 ; \mathrm{P}<0.001\right)$. Subsequently, the AO-F staining method was used to detect positive staining cells in 8 healthy volunteers (control group), and 112 non-metastatic and 27 metastatic RCC patients. The positive staining rate was $13.67 \%$ $(19 / 139)$ in RCC patients, while none of the control group was positive. The AO-F positive staining rate was not significantly different between the metastatic and non-metastatic patients according to age, gender, the pathological pattern, T2/3 (according to the Tumor-Node-Metastasis classification) or Fuhrman grade, while there was a significant difference according to T1. The positive staining rate was $8.93 \%(10 / 112)$ for non-metastatic patients and 33.33\% (9/27) for metastatic patients, which showed a significant difference $(\mathrm{P}<0.05)$. In 112 non-metastatic and 27 metastatic patients, the positive staining rate was not significantly associated with gender, age, tumor size, the pathological pattern, T classification, Fuhrman
\end{abstract}

Correspondence to: Mrs. Fuling Ma or Mr. Ning Jiang, Department of Urology, Tianjin Institute of Urology, The Second Hospital of Tianjin Medical University, 23 Pingjiang Road, Hexi, Tianjin 300211, P.R. China

E-mail: fulingmatjmu@126.com

E-mail: jnbear@126.com

Key words: circulating tumor cells, acridine orange fluorescence, renal cell carcinoma, cytodiagnosis grade, the presence of a lesion or metastasis to the lungs. The present study demonstrated that the method of CTC staining with AO-F, which has high reproducibility and specificity, was feasible for identifying CTCs and warrants further study.

\section{Introduction}

In total, $90 \%$ of renal cell carcinoma (RCC)-related mortalities result from metastasis and invasion (1). Surgery is the cornerstone treatment for RCC, as it is insensitive to radiotherapy and chemotherapy. RCC lacks specific biomarkers, such that it is difficult to diagnose and predict recurrence or metastasis (2). Therefore, research on novel markers is among the most active areas in RCC science. Circulating tumor cells (CTCs) are malignant cells derived from primary lesions that invade into the circulatory system; they are distributed throughout the body and eventually form micro-metastatic deposits (3). CTCs, which can indicate prognosis and reveal the behavior of tumor metastasis, instruct clinically individualized treatment and are the focus of oncology research (4-6).

To date, many methods have been used to detect CTCs, although a recognized gold-standard method is still lacking. For decades, the acridine orange fluorescence (AO-F) staining method has been applied to the analysis of hydrothorax, ascites and urine and other body fluids, and it is considered a unique liquid biopsy technique (7-9). As a result of its high specificity, reproducibility and low cost $(10,11)$, clinical doctors have approved the clinical application of the AO-F staining method to the auxiliary diagnosis of tumors and follow-up.

The present study explored the development of a novel AO-F staining method for monitoring prognosis and metastasis via the detection of CTCs, and further validated its clinical significance in RCC patients.

\section{Materials and methods}

Patients. The present study was approved by the Ethics Committee of The Second Hospital of Tianjin Medical University, China, and written informed consent was obtained from all patients. In total, 112 non-metastatic and 27 metastatic RCC patients (aged 28-86 years; average age of $58.47 \pm 11.26$ years) at The Second Hospital of Tianjin Medical University were included in the present study. Blood samples 
were collected from the patients from September 2013 to June 2015. The non-metastatic patients had not accepted any other treatment for 2 months following a radical nephrectomy. The metastatic patients had sufficient clinical or radiographic evidence to prove that their tumors had metastasized, and had not accepted any standard treatments. A further 8 healthy volunteers (aged 26-79 years; average age of 50.10 \pm 16.88 years) recruited online formed the control group.

Cell culture. Fresh canary yellow tumor tissues ( $\geq 10 \mathrm{~g}$ ) were collected from each of six patients who were confirmed by pathological diagnosis as having clear cell RCC (CCRCC). The tissues were rinsed with PBS and cut into pieces. Single cell suspensions were prepared by enzymatic digestion with pancreatic enzymes. Cells were cultured in RPMI-1640 medium (Thermo Fisher Scientific, Inc., Waltham, MA, USA) supplemented with $20 \%$ heat-inactivated fetal bovine serum (FBS; Thermo Fisher Scientific, Inc., ) and 1\% streptomycin/penicillin at $37^{\circ} \mathrm{C}$ and $5 \% \mathrm{CO}_{2}$. Following three passages, primary tumor cells were obtained. Simultaneously, the renal cell line 769-P (American Type Culture Collection, Manassas, VA, USA) was cultured in RPMI-1640 medium supplemented with $10 \% \mathrm{FBS}$ and $1 \%$ streptomycin/penicillin at $37^{\circ} \mathrm{C}$ and $5 \% \mathrm{CO}_{2}$. Cells were centrifuged at $401 \times \mathrm{g}$ for $10 \mathrm{~min}$ at $37^{\circ} \mathrm{C}$, and then counted under an inverted microscope upon being stained with $4 \%$ Trypan blue dye.

Establishment of the CTC model. Dead tumor cells were prepared by heating the $769-\mathrm{P}$ cells at $75^{\circ} \mathrm{C}$ for $30 \mathrm{~min}$ in a water bath. Live tumor cells were treated with PBS. The two groups of cells (live and dead) were suspended and diluted with PBS progressively to 10, 50, 100, 200 and 500 cells/tube. The cells in each tube were mixed with $10^{6}$ nucleated cells to evaluate the specificity and reproducibility of the AO-F staining method. Next, the cells were centrifuged at $750 \times g$ for $15 \mathrm{~min}$ at $37^{\circ} \mathrm{C}$, and fixed at $37^{\circ} \mathrm{C}$ for $30 \mathrm{~min}$ with a mixture of glacial acetic acid, chloroform and dehydrated alcohol at a 1:3:6 ratio. Sediments were dropped onto slides and stained with $\mathrm{AO}-\mathrm{F}$, and the positive staining rates of the live and dead cells were calculated. The positive staining rate was estimated by counting the number of AO-F-positively stained cells in 100 cells under five random microscopic visions (magnification, $\mathrm{x} 200$ ). A total of $5 \mathrm{ml}$ fasting blood was obtained from the control group to enrich the number of nucleated cells. 769-P cells were suspended and diluted with PBS progressively to $10,50,100,200$ and 500 cells/tube. The cells in each tube were mixed with $10^{6}$ nucleated cells to evaluate the specificity and reproducibility of the AO-F staining method. The suspension was loaded onto slides and stained with AO-F. The abovementioned procedures were repeated 4 times.

Clinical trial. A total of $6 \mathrm{ml}$ fasting blood was drawn from 112 non-metastatic patients 2 months after the radical nephrectomy and from 27 metastatic patients once metastasis after radical nephrectomy had been confirmed. All blood samples were processed in the following way: Red blood cells were lysed with Red Blood Cell Lysis Buffer (Wuhan Boster Biological Technology, Ltd., Wuhan, China), and the samples were fixed at $37^{\circ} \mathrm{C}$ for $30 \mathrm{~min}$, smeared and stained
Table I. Acridine orange fluorescence-positive staining rate in peripheral blood.

\begin{tabular}{lrc}
\hline Group & $\mathrm{n}$ & Positive rate, $\mathrm{n}(\%)$ \\
\hline Non-metastatic RCC & 112 & $10(8.93)$ \\
Metastatic RCC & 27 & $9(33.33)$ \\
Total RCC & 139 & $19(13.67)$ \\
Controls & 8 & $0(0.00)$ \\
\hline
\end{tabular}

RCC, renal cell carcinoma.

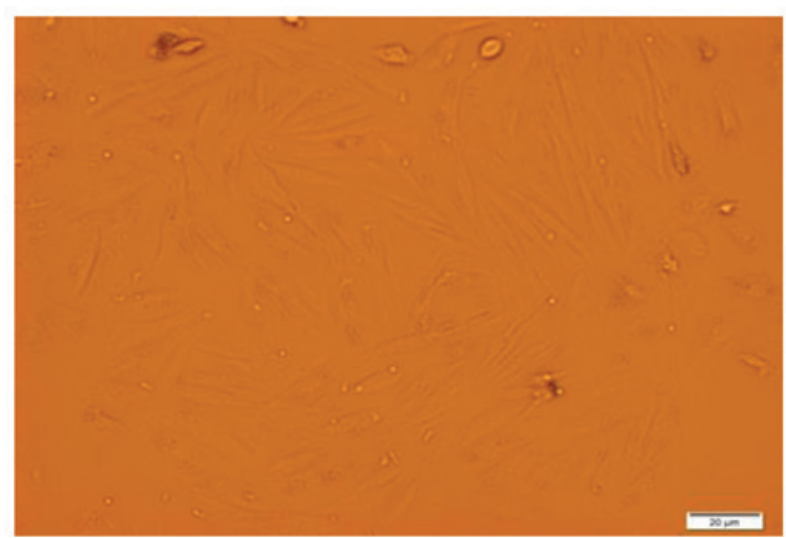

Figure 1. Growth and adhesion of the primary tumor cells were observed on day 21 of culture under an inverted microscope (magnification, x200).

with AO-F. A total of 10 slides were prepared for each 6-ml sample.

AO-F staining. The slides were soaked in AO-F solution $(0.01 \%)$ for $3 \mathrm{~min}$ and washed with PBS, then immersed in calcium chloride solution for $3 \mathrm{~min}$ and rewashed with PBS. The slides were mounted for observation under a fluorescence microscope.

Outcome interpretation. There is no accepted standard for the AO-F staining method. The following classification was used in the present study: i) For AO-F-positively stained cells (live cells), the volume of the cells and nuclei were increased, the shape of the nuclei varied and the nuclei were bright yellow, with the cytoplasm a flame-like orange; and ii) for AO-F-negatively stained cells, the nuclei of leucocytes or dead tumor cells were green, while the cytoplasm was not colored. Some abnormal cells were observed on the slides and whether they were leucocytes or tumor cells was uncertain; these cells were considered negative. According to cellular morphology and cytochemistry, it was decided whether cells were positive or negative. All the slides were judged by two blinded pathologists, and by a third pathologist if the result was inconsistent.

Statistical analysis. All results are presented as the positive rate, and the differences in the positive rates between different groups were analyzed by one-way analysis of variance. Comparisons of the groups for enumeration data were 

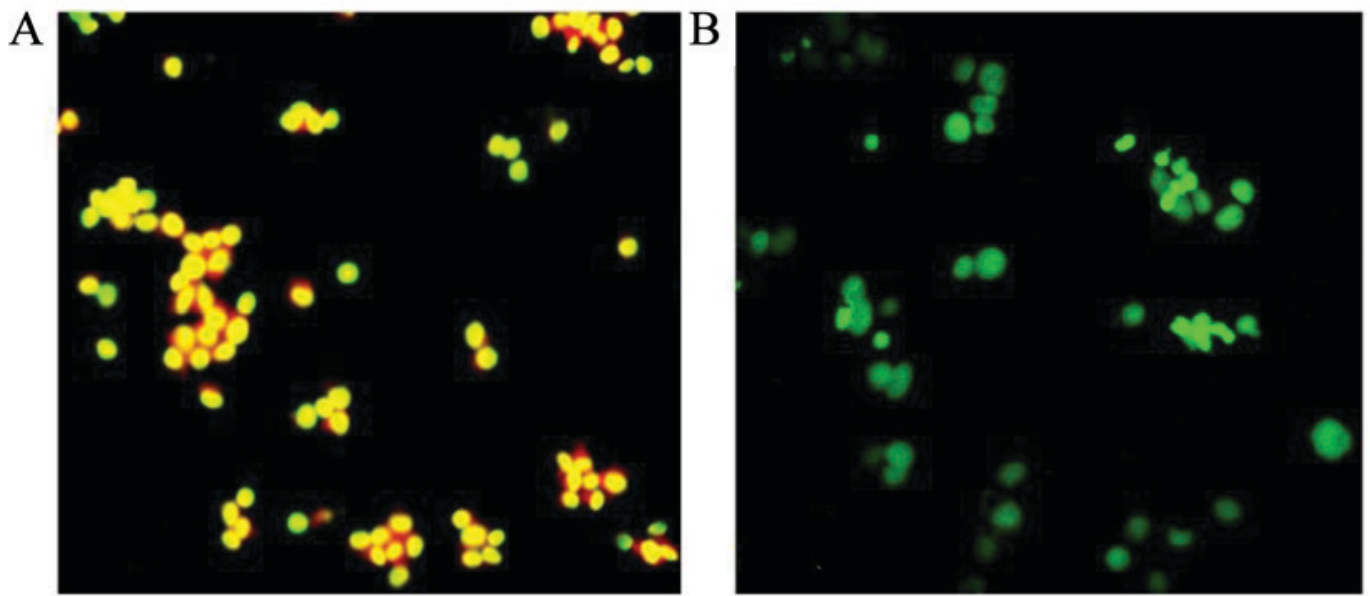

Figure 2. Microscopic images of live and dead tumor cells stained with acridine orange (magnification, x200). (A) Representative image of cells in the live group. The nuclei were bright yellow and their shape varied; the cytoplasm was a flame-like orange. (B) Representative image of cells in the dead group. The nuclei of the cells were green, while the cytoplasm was not colored.

performed using $\chi^{2}$ tests and Fisher's exact test. $\mathrm{P}<0.05$ was considered to indicate a statistically significant difference. SPSS 17.0 software (SPSS Inc., Chicago, IL, USA) was used for all analyses.

\section{Results}

Characteristics of cells in the primary culture. Tumor tissue was collected from 6 patients with CCRCC, and primary tumor cell cultures were successfully established for 2 of the 6 CCRCC cases. Thus, the success rate was $33.33 \%$. The cells grew well and fast, were varied in size and shape, and were diverse in terms of the nuclear-cytoplasmic ratio. The nuclei had apparent atypia (Fig. 1).

AO-F staining characteristics of cells in the live and dead tumor cell groups. Fig. 2A shows the live tumor cells. Nuclei of the primary tumor cells or 769-P cells were bright yellow, and the cytoplasm was a flame-like orange. Fig. 2B shows the dead primary tumor cells or dead 769-P cells. The nuclei of the dead cells were bright green and the cytoplasm was not a flame-like orange. The positive staining rate in the live cell group was $93.4 \pm 3.0 \%$ (Fig. 3). The dead cell group did not show any positive AO-F staining.

Specificity and reproducibility of the AO-F method. The detection sensitivity was calculated as the ratio of the number of AO-F positively stained cells to the number of total cells in the system. The detection sensitivities of the four groups $(50,100,200$ and 500 cells/tube) were $10.2 \pm 3.8,9.2 \pm 2.3$, $10.8 \pm 2.6$ and $10.5 \pm 1.9 \%$, respectively. No significant difference was found among the four groups $(\mathrm{F}=1.001 ; \mathrm{P}>0.05)$. The average rate in the four groups was $10.16 \pm 2.73 \%$. The quality control chart of the rate is presented in Fig. 4. The more cells that were added into the blood, the more AO-F-positive cells that were recovered. AO-F-positive cells were also detected when 10 cells were added to the blood.

Application of the AO-F staining method to patients and the control group. Fig. 5A shows images of the AO-F-negative cells from the 8 controls and 120 of the 139 cases in which CTCs were not detected. Two types of cells can be seen in Fig. 5B, which shows images of the cells in 19 of the 139 cases. One type was mainly AO-F-negative cells, while the other was $\mathrm{AO}-\mathrm{F}$-positive cells. The $\mathrm{AO}-\mathrm{F}$ positive staining rate in the peripheral blood of each group has been shown in Table I.

Association between patient characteristics and positive-staining rate in non-metastatic and metastatic patients. The positive staining rate was $13.67 \%$ in 139 patients with RCC, and it was not significantly associated with gender, age, tumor size, the pathological pattern, $\mathrm{T}$ classification or Fuhrman grade $(\mathrm{P}>0.05)$. However, there was a significant correlation between the positive rate and metastasis (Table II). In 112 non-metastatic and 27 metastatic patients, the positive staining rate was not significantly associated with gender, age, tumor size, the pathological pattern, $T$ classification, Fuhrman grade, presence of a lesion or metastasis to the lungs ( $\mathrm{P}>0.05$; Tables III and IV). The positive staining rate was $8.93 \%(10 / 112)$ in non-metastatic and $33.33 \%(9 / 27)$ in metastatic patients, which was significantly different $(\mathrm{P}<0.05$; Table V).

Comparison of the AO-F positive-staining rate (\%) in 112 non-metastatic and 27 metastatic patients. The AO-F positive staining rate showed no significant difference between non-metastatic and metastatic patients according to age, gender, the pathological pattern, T2/3 classification or Fuhrman grade, while a significant difference was found between the metastatic and non-metastatic patients with a $\mathrm{T} 1$ classification (Table V).

\section{Discussion}

RCC is one of the most common tumors of the urinary system and metastasis is the main reason for mortality following a radical nephrectomy. The key step in metastasis is initiated by CTCs, which are shed from the primary lesions, invade into the circulatory system, proliferate and form metastases under appropriate conditions $(2,12)$. Therefore, it is important 


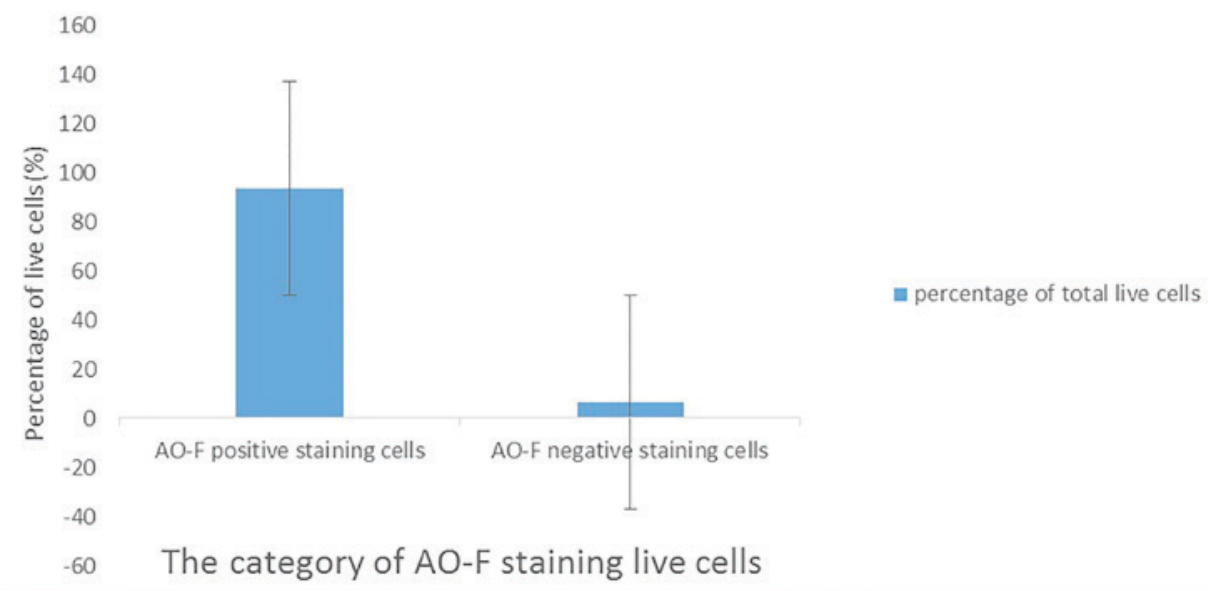

Figure 3. Binding rate of the primary tumor cells to the AO-F dye. AO-F, acridine orange fluorescence.

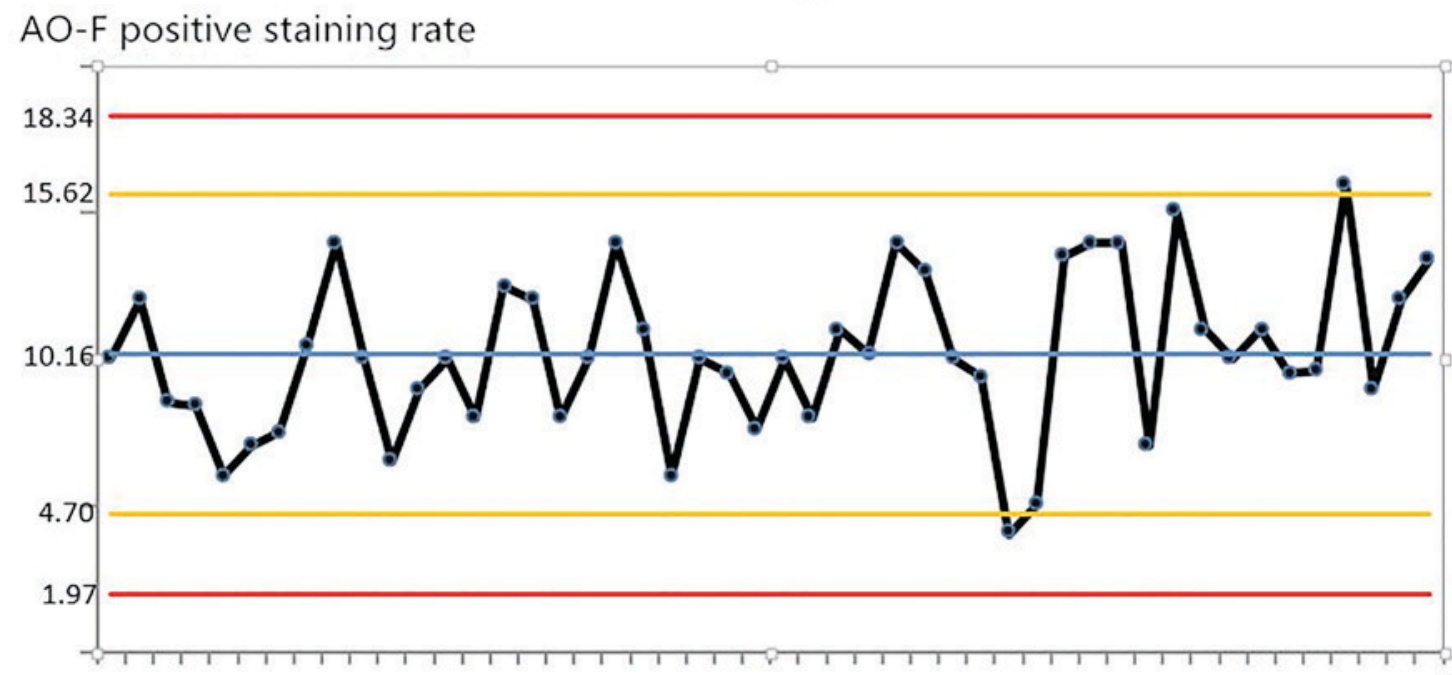

The Maximum Allowable Line Warning Line

The Target Value Line

Warning Line

The Minimum Allowable Line

\section{$1 \quad 3 \quad 5 \quad 7 \quad 9 \quad 11131517192123252729313335373941434547$ Spiked cell Num}

Figure 4. Quality control chart of the AO-F-positive staining rate of spiked cells, indicating the number of cells added to build the CTC models. The positive-staining rate was calculated as the ratio of the number of AO-F positively stained cells to the total number of cells added into the system. The target value line shows the mean AO-F-positive staining rate of the four groups. The measured value was controlled within the range of random fluctuations from the top to the bottom lines. Measured values outside the maximum or minimum allowable lines (which were calculated using analysis of variance) were out of range. $\mathrm{AO}-\mathrm{F}$, acridine orange fluorescence; Num, number.
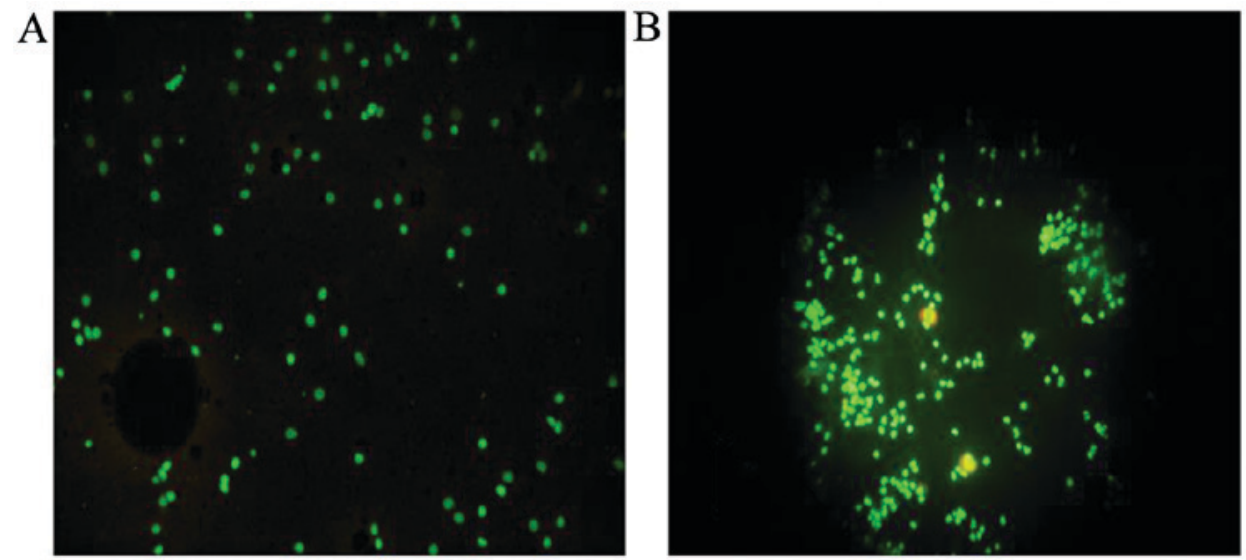

Figure 5. AO-F staining characteristics in patients with RCC (magnification, x100). (A) AO-F-negative staining cells in RCC patients. (B) AO-F-positive staining cells (yellow cells) in RCC patients. AO-F, acridine orange fluorescence; RCC, renal cell carcinoma. 
Table II. Clinical parameters and acridine orange fluorescence-positive staining rate in 139 patients with RCC.

\begin{tabular}{|c|c|c|c|c|c|}
\hline Parameter & Positive (n) & Negative (n) & Total (n) & Positive rate $(\%)$ & P-value \\
\hline Age at diagnosis (years) & & & & & 0.337 \\
\hline$\leq 60$ & 10 & 49 & 59 & 16.95 & \\
\hline$>60$ & 9 & 71 & 80 & 11.25 & \\
\hline Gender & & & & & 0.363 \\
\hline Male & 12 & 88 & 100 & 12.00 & \\
\hline Female & 7 & 32 & 39 & 17.95 & \\
\hline Tumor size $(\mathrm{cm})$ & & & & & 0.809 \\
\hline$\leq 4$ & 11 & 73 & 84 & 13.10 & \\
\hline$>4$ & 8 & 47 & 55 & 14.55 & \\
\hline Pathological pattern & & & & & 0.321 \\
\hline CCRCC & 12 & 89 & 101 & 11.89 & \\
\hline Other & 7 & 31 & 38 & 18.42 & \\
\hline $\mathrm{T}$ classification & & & & & 0.702 \\
\hline $\mathrm{T} 1$ & 7 & 96 & 103 & 6.80 & \\
\hline $\mathrm{T} 2$ & 9 & 20 & 29 & 31.03 & \\
\hline $\mathrm{T} 3$ & 3 & 4 & 7 & 42.85 & \\
\hline $\mathrm{T} 4$ & - & - & - & - & \\
\hline Fuhrman grade & & & & & 0.050 \\
\hline I & 5 & 18 & 23 & 21.74 & \\
\hline II & 14 & 84 & 98 & 14.29 & \\
\hline III & 0 & 18 & 18 & 0.00 & \\
\hline Metastasis & & & & & 0.017 \\
\hline Yes & 9 & 18 & 27 & 33.33 & \\
\hline No & 10 & 102 & 112 & 8.93 & \\
\hline
\end{tabular}

CCRCC, clear cell renal cell carcinoma.

to monitor the recurrence and metastasis once CTCs have been detected in the circulatory system $(13,14)$. Bluemke et al $(15)$ demonstrated that CTCs are an independent prognostic factor that correlates with metastasis. The CELLSEARCH ${ }^{\circledR}$ System, which was approved by the Food and Drug Administration, has been widely used to monitor disease progression in breast, colorectal and prostatic carcinomas by detecting biomarkers to identify CTCs (16-18). However, it is limited when applied to RCC patients, whose tumor cells lack a specific biomarker after invading into the circulatory system from primary lesions (19). Therefore, it is necessary to develop a novel method to predict recurrence or metastasis in RCC.

The AO-F staining method is a kind of unique liquid biopsy technique that has been used in a wide variety of microbiological and oncological fields, including microorganism, parasite, bacteria and tumor cell research (20-23). Duan et al (24) observed that that the AO-F dye was unable to label monodansylcadaverine-labeled autophagic vesicles with rims decorated with light chain 3 (25), an autophagy related lipidation, when nitric oxide was depleted in estrogen receptor-positive MCF7 breast cancer cells. Citterio et al (26) evaluated cell viability using the AO-F staining method in Saccharomyces cerevisiae. Li et al (8) demonstrated that high-grade upper urinary tract urothelial carcinoma could be predicted through urinary cytology with AO-F staining. Furthermore, in another study, AO-F could specifically combine with DNA and RNA in different ways to produce different fluorescence (27). The fluorescence intensity of $\mathrm{AO}-\mathrm{F}$ is dependent on the quantity of DNA in the cell nucleus and RNA in the cytoplasm. AO-F technology could integrate two characteristics of cells, morphology and chemistry, to determine whether the cells are benign or malignant in the absence of a suitable biomarker. The metabolism of CTCs tends to be vigorous, and the activity of their DNA or RNA polymerases is higher than that of leucocytes. Therefore, their DNA or RNA content is significantly increased, thus CTCs could be distinguished from leucocytes under a fluorescence microscope (28).

In the present study, the positive staining rate in the live cell group was $93.4 \pm 3.0 \%$, which revealed that the $\mathrm{AO}-\mathrm{F}$ dye was highly sensitive for tumor cells in the live cells group, but not in the dead cells group. Subsequently, a CTC model was established, which demonstrated that the AO-F positive staining rate in the four groups $(50,100,200$ and 500 cells/tube) was not significantly different, and that it would not change along with the number of tumor cells in the peripheral blood. The recovery rate of AO-F-positively stained cells was relatively low. In a previous study, a high recovery 
Table III. Clinical parameters and acridine orange fluorescence-positive staining rate of CTCs in the blood samples of 112 non-metastatic patients with renal cell carcinoma.

\begin{tabular}{|c|c|c|c|c|c|c|}
\hline Parameter & Positive (n) & Negative (n) & Total (n) & Positive rate $(\%)$ & $\chi^{2}$ & P-value \\
\hline Age at diagnosis (years) & & & & & 0.962 & 0.961 \\
\hline$\leq 60$ & 6 & 62 & 68 & 8.82 & & \\
\hline$>60$ & 4 & 40 & 44 & 9.10 & & \\
\hline Gender & & & & & 0.865 & 0.863 \\
\hline Male & 7 & 74 & 81 & 8.64 & & \\
\hline Female & 3 & 28 & 31 & 9.68 & & \\
\hline Tumor size (cm) & & & & & 0.612 & 0.608 \\
\hline$\leq 4$ & 7 & 63 & 70 & 10.00 & & \\
\hline$>4$ & 3 & 39 & 42 & 7.14 & & \\
\hline Pathological pattern & & & & & 0.855 & 0.853 \\
\hline CCRCC & 8 & 79 & 87 & 9.20 & & \\
\hline Other & 2 & 23 & 25 & 8.00 & & \\
\hline $\mathrm{T}$ classification & & & & & 0.292 & 0.242 \\
\hline $\mathrm{T} 1$ & 3 & 83 & 86 & 3.49 & & \\
\hline $\mathrm{T} 2$ & 6 & 17 & 23 & 26.09 & & \\
\hline $\mathrm{T} 3$ & 1 & 2 & 3 & 33.33 & & \\
\hline $\mathrm{T} 4$ & - & - & - & - & & \\
\hline Fuhrman grade & & & & & 0.133 & 0.301 \\
\hline I & 2 & 11 & 13 & 15.38 & & \\
\hline II & 8 & 74 & 82 & 9.76 & & \\
\hline III & 0 & 17 & 17 & 0.00 & & \\
\hline IV & - & - & - & - & & \\
\hline
\end{tabular}

CCRCC, clear cell renal cell carcinoma.

rate $(>80 \%)$ was achieved with defined numbers of MCF-7 and HepG2 cancer cells using a microsieve lab-chip device, which had the potential value of allowing rapid enumeration of CTCs using fluorescence in situ hybridization for cancer metastasis analysis (29). As one of the most efficient immunomagnetic isolation technologies, bio-ferrography had a significant recovery rate of $>95 \%$ when isolating 100 CTCs that were highly positive for epidermal growth factor receptor from $1 \mathrm{ml}$ whole blood (30). Yusa et al (31) used the technology of a three-dimensional palladium filter to isolate CTCs, and $>85 \%$ of tumor cells were recovered in cell spike experiments. The sensitivity of this method was inferior to that of the method used in the present study, as reported previously $(27,28)$. Various steps, including centrifugation, counting, and rinsing, as well as the inherent characteristics of AO-F, such as the weak photostability of free AO-F, may cause cell loss to varying degrees (32). Furthermore, the present study found a positive correlation between the number of AO-F-positive cells and the total number of cells in the system. AO-F-positive cells were not found in the 8 blood samples from healthy volunteers. Therefore, although the AO-F staining method could cause cell losses, the results of the present study suggested that this method had the advantages of high reproducibility and specificity.

The present study applied the AO-F staining method to 139 patients with $\mathrm{RCC}$, and the positive staining rate was
$13.67 \%$. Of the 139 cases, 112 were without distant metastasis and 27 were with distant metastasis, with a ratio of 4.15:1. The positive staining rate was not significantly associated with gender, age, tumor size, the pathological pattern, T classification or Fuhrman grade in the 139 patients with RCC. The positive staining rate was 8.93 and $33.33 \%$ in 112 non-metastatic and 27 metastatic patients, respectively, and there was a significant difference between them. The result that the positive staining rate of CTCs was associated with metastasis was consistent with previous studies $(30,31)$. Rossi et al (33) used CTCs to predict responses to sunitinib in metastatic RCC, and demonstrated that the presence of CTCs was associated with distant metastasis. Tanaka et al (34) analyzed 94 primary lung cancer patients without distant metastasis and 31 primary lung cancer patients with distant metastasis using the CELLSEARCH ${ }^{\circledR}$ System, and found that there was a significant difference in CTC counts between them and demonstrated that CTCs were the main indicator of distant metastasis. However, the diagnostic significance of CTCs was controversial in various previous studies $(13,32,33)$, and its value requires further investigation.

In the present study, the presence of CTCs was not significantly associated with age, gender, tumor size, the pathological pattern, T classification or Fuhrman grade in 112 non-metastatic patients. Bluemke et al (15) and McKiernan et al (35) also reported that there was no correlation between the presence 
Table IV. Clinical parameters and acridine orange fluorescence-positive staining rate of CTCs in the blood samples of 27 metastatic patients with renal cell carcinoma.

\begin{tabular}{|c|c|c|c|c|c|c|}
\hline Parameter & Positive (n) & Negative (n) & Total (n) & Positive rate $(\%)$ & $\chi^{2}$ & P-value \\
\hline Age at diagnosis (years) & & & & & 1.350 & 0.683 \\
\hline$\leq 60$ & 3 & 9 & 12 & 25.00 & & \\
\hline$>60$ & 6 & 9 & 15 & 40.00 & & \\
\hline Gender & & & & & 2.842 & 0.375 \\
\hline Male & 5 & 14 & 19 & 26.32 & & \\
\hline Female & 4 & 4 & 8 & 50.00 & & \\
\hline Tumor size $(\mathrm{cm})$ & & & & & 0.150 & 0.928 \\
\hline$\leq 4$ & 3 & 7 & 10 & 30.00 & & \\
\hline $4-7$ & 4 & 8 & 12 & 33.33 & & \\
\hline$>4$ & 2 & 3 & 5 & 40.00 & & \\
\hline Pathological pattern & & & & & 0.297 & 0.695 \\
\hline CCRCC & 4 & 10 & 14 & 28.56 & & \\
\hline Other & 5 & 8 & 13 & 38.46 & & \\
\hline T classification & & & & & 1.985 & 0.077 \\
\hline $\mathrm{T} 1$ & 4 & 13 & 17 & 25.53 & & \\
\hline $\mathrm{T} 2$ & 3 & 3 & 6 & 50.00 & & \\
\hline $\mathrm{T} 3$ & 2 & 2 & 4 & 50.00 & & \\
\hline $\mathrm{T} 4$ & - & - & - & - & & \\
\hline Fuhrman grade & & & & & 0.675 & 0.714 \\
\hline I & 3 & 7 & 10 & 30.00 & & \\
\hline II & 6 & 10 & 16 & 37.50 & & \\
\hline III & 0 & 1 & 1 & 0.00 & & \\
\hline IV & - & - & - & - & & \\
\hline Presence of lesions & & & & & 0.000 & 1.000 \\
\hline Yes & 9 & 18 & 27 & 33.33 & & \\
\hline No & 4 & 8 & 12 & 33.33 & & \\
\hline Metastasis of the lungs & & & & & 0.675 & 0.683 \\
\hline Yes & 3 & 9 & 12 & 25.00 & & \\
\hline No & 6 & 9 & 15 & 40.00 & & \\
\hline
\end{tabular}

CCRCC, clear cell renal cell carcinoma.

of CTCs and tumor size in RCC. However, Pinzani et al (36) demonstrated that the messenger RNA levels of tyrosinase, which can be taken as an indirect parameter correlated to the number of CTCs, were significantly correlated with tumor dimension and disease-free and overall survival through reverse transcription-quantitative polymerase chain reaction analysis of blood from 41 patients with uveal melanoma. In the present study, there was no correlation between the positive staining rate and age, gender, tumor size, the pathological pattern, T classification, Fuhrman grade, presence of a lesion or metastasis to the lungs in 27 metastatic patients. However, Tanaka et al (34) also reported that the detection level of CTCs in lung cancer was higher as the degree of malignancy increased. The above result is inconsistent with the results of the present study. The different detection levels of CTCs associated with different pathological patterns may result from the sample size and various origins of the tumor. According to the present results, clinical stage and Fuhrman grade appear to be important in therapy and prognosis. However, in the present study, AO-F positively stained cells were found regardless of the tumor size (T1, T2, T3 and T4) or Fuhrman grade (GI, GII, GIII and GIV). The AO-F positive staining rate was not significantly different between the non-metastatic patients and metastatic patients according to age, gender, the pathological pattern, T2/3 classification or Fuhrman grade, while a significant difference was found between the metastatic and non-metastatic patients with a $\mathrm{T} 1$ classification. This needs to be verified further.

El-Naggar et al (37) demonstrated that RNA was a valuable index in the pathological assessment of RCC, and that there was a correlation between a higher proliferative index and DNA aneuploidy in RCC by AO-flow cytometric analysis. In the present study, there were no clinical symptoms or imaging data to support metastases or recurrence in the 112 non-metastatic patients, although AO-F positive cells were detected in these patients. Although AO-F positive staining did not always mean 
Table V. Comparison of acridine orange fluorescence-positive staining rate of CTCs in the blood samples of 112 non-metastatic and 27 metastatic patients with renal cell carcinoma.

\begin{tabular}{|c|c|c|c|}
\hline Parameter & $\begin{array}{c}\text { Non-metastatic } \\
\text { patients }(\%)\end{array}$ & $\begin{array}{c}\text { Metastatic } \\
\text { patients (\%) }\end{array}$ & P-value \\
\hline \multicolumn{4}{|c|}{$\begin{array}{l}\text { Age at diagnosis } \\
\text { (years) }\end{array}$} \\
\hline$\leq 60$ & 8.82 & 25.00 & 0.083 \\
\hline$>60$ & 9.10 & 40.00 & 0.439 \\
\hline \multicolumn{4}{|l|}{ Gender } \\
\hline Male & 8.64 & 26.32 & 0.285 \\
\hline Female & 9.68 & 50.00 & 1.000 \\
\hline \multicolumn{4}{|c|}{ Tumor size (cm) } \\
\hline$\leq 4$ & 10.00 & 30.00 & 1.000 \\
\hline$>4$ & 7.14 & 35.29 & 0.225 \\
\hline \multicolumn{4}{|c|}{ Pathological pattern } \\
\hline CCRCC & 9.20 & 28.56 & 0.109 \\
\hline Other & 8.00 & 38.46 & 0.405 \\
\hline \multicolumn{4}{|c|}{ T classification } \\
\hline $\mathrm{T} 1$ & 3.49 & 23.53 & $0.029^{\mathrm{a}}$ \\
\hline $\mathrm{T} 2$ & 26.09 & 50.00 & 1.000 \\
\hline $\mathrm{T} 3$ & 33.33 & 50.00 & 1.000 \\
\hline $\mathrm{T} 4$ & - & - & \\
\hline \multicolumn{4}{|c|}{ Fuhrman grade } \\
\hline I & 15.38 & 30.00 & 0.206 \\
\hline II & 9.76 & 37.50 & 0.317 \\
\hline III & 0.00 & 0.00 & \\
\hline IV & - & - & \\
\hline
\end{tabular}

${ }^{\mathrm{a}} \mathrm{P}<0.05$. CCRCC, clear cell renal cell carcinoma.

that metastasis has occurred, the possibility of metastasis or recurrence was higher in patients with positively stained cells than in those with negatively stained cells. Smerage et al (38) demonstrated that the presence of CTCs was an adverse prognostic factor in the Southwest Oncology Group S0500 clinical trial of breast cancer. In some cases, the maximum number of CTCs appeared in circulation during the early stage of tumor development (39). A recent mathematical model was developed by El-Naggar et al (37) to estimate the tumor size and the CTC load prior to the formation of the first metastasis from a primary breast cancer tumor. The results confirmed the early appearance of CTCs in small primary tumors prior the formation of the first metastasis, which has been confirmed in both epithelial and non-epithelial tumors (40). It is well known that metastasis is a late event in cancer progression, and that there is quite a long period from the appearance of CTCs to the formation of metastases (41); thus, early intervention may effectively control metastasis. It was shown that $66.66 \%$ of patients with metastatic RCC had no AO-F-positive cells. This may have been due to fluctuations in the rate of CTC release into the blood, the sample volume or inherent characteristics of AO-F. Furthermore, the number of CTCs alter from individual to individual and at different points in time due to the constructional and functional heterogeneity of cancer, the physical state of the host and their dynamic variation during disease progression (42-45). Although the detection of CTCs may be useful for predicting the recurrence and prognosis of RCC, the particular mechanisms are not currently clear.

In conclusion, the present study demonstrated that the AO-F staining method was able to identify CTCs, and may be used to screen for CTCs in high-risk patients to assist clinical treatment and diagnosis. It also had the advantages of convenience, less-invasiveness and lower costs $(11,46)$. Therefore, the AO-F staining method is worthy of further research.

\section{Acknowledgements}

The present study was supported by the Tianjin Education Commission Fund (grant no. 20140117).

\section{References}

1. Chaffer CL and Weinberg RA: A perspective on cancer cell metastasis. Science 331: 1559-1564, 2011.

2. Greef B and Eisen T: Medical treatment of renal cancer: New horizons. Br J Cancer 115: 505-516, 2016.

3. Attard G, Swennenhuis JF, Olmos D, Reid AH, Vickers E, A'Hern R, Levink R, Coumans F, Moreira J, Riisnaes R, et al: Characterization of ERG, AR and PTEN gene status in circulating tumor cells from patients with castration-resistant prostate cancer. Cancer Res 69: 2912-2918, 2009.

4. Lu CY, Tsai HL, Uen YH, Hu HM, Chen CW, Cheng TL, Lin SR and Wang JY: Circulating tumor cells as a surrogate marker for determining clinical outcome to mFOLFOX chemotherapy in patients with stage III colon cancer. Br J Cancer 108: 791-797, 2013.

5. Denéve E, Riethdorf S, Ramos J, Nocca D, Coffy A, Daurès JP, Maudelonde T, Fabre JM, Pantel K and Alix-Panabières C: Capture of viable circulating tumor cells in the liver of colorectal cancer patients. Clin Chem 59: 1384-1392, 2013.

6. Krebs MG, Hou JM, Sloane R, Lancashire L, Priest L, Nonaka D, Ward TH, Backen A, Clack G, Hughes A, et al: Analysis of circulating tumor cells in patients with non-small cell lung cancer using epithelial marker-dependent and -independent approaches. J Thorac Oncol 7: 306-315, 2012.

7. Prosser E, Cox D, O'Kennedy R, Carroll K and van der Putten W: Effects of coumarins, haematoporphyrins and acridine orange on the viability and growth of Landshutz ascites tumour cells, in the presence and absence of photoradiation. Cancer Lett 52: 71-77, 1990.

8. Li J, Zhang Z, Wang J, Zhang C, Li H and Xu Y: Urinary cytology with acridine orange fluorescence is highly valuable for predicting high-grade upper urinary tract urothelial carcinoma. Int J Clin Exp Pathol 7: 774-778, 2014.

9. Thome MP, Filippi-Chiela EC, Villodre ES, Migliavaca CB, Onzi GR, Felipe KB and Lenz G: Ratiometric analysis of acridine orange staining in the study of acidic organelles and autophagy. J Cell Sci 129: 4622-4632, 2016.

10. Xie ZB, Yao L, Jin C and Fu DL: Circulating tumor cells in pancreatic cancer patients: Efficacy in diagnosis and value in prognosis. Discov Med 22: 121-128, 2016.

11. Guo J, Pui TS, Ban YL, Rahman AR and Kang Y: Electrokinetic analysis of cell translocation in low-cost microfluidic cytometry for tumor cell detection and enumeration. Ieee Trans Biomed Eng 60: 3269-3275, 2013.

12. Chen F, Liu X, Cheng Q, Zhu S, Bai J and Zheng J: RUNX3 regulates renal cell carcinoma metastasis via targeting miR-6780a-5p/E-cadherin/EMT signaling axis. Oncotarget 2016 (Epub ahead of print).

13. Gakhar G, Navarro VN, Jurish M, Lee GY, Tagawa ST, Akhtar NH, Seandel M, Geng Y, Liu H, Bander NH, et al: Circulating tumor cells from prostate cancer patients interact with E-selectin under physiologic blood flow. PLoS One 8: e85143, 2013.

14. Gazzaniga P, Gradilone A, de Berardinis E, Busetto GM, Raimondi C, Gandini O, Nicolazzo C, Petracca A, Vincenzi B, Farcomeni A, et al: Prognostic value of circulating tumor cells in nonmuscle invasive bladder cancer: A CellSearch analysis. Ann Oncol 23: 2352-2356, 2012. 
15. Bluemke K, Bilkenroth U, Meye A, Fuessel S, Lautenschlaeger C, Goebel S, Melchior A, Heynemann H, Fornara P and Taubert H: Detection of circulating tumor cells in peripheral blood of patients with renal cell carcinoma correlates with prognosis. Cancer Epidemiol Biomarkers Prev 18: 2190-2194, 2009.

16. Joosse SA, Gorges TM and Pantel K: Biology, detection, and clinical implications of circulating tumor cells. EMBO Mol Med 7: 1-11, 2014.

17. Allen JE, Saroya BS, Kunkel M, Dicker DT, Das A, Peters KL, Joudeh J, Zhu J and El-Deiry WS: Apoptotic circulating tumor cells (CTCs) in the peripheral blood of metastatic colorectal cancer patients are associated with liver metastasis but not CTCs. Oncotarget 5: 1753-1760, 2014.

18. Rossi E, Rugge M, Facchinetti A, Pizzi M, Nardo G, Barbieri V, Manicone M, De Faveri S, Chiara Scaini M, Basso U, et al: Retaining the long-survive capacity of Circulating Tumor Cells (CTCs) followed by xeno-transplantation: Not only from metastatic cancer of the breast but also of prostate cancer patients. Oncoscience 1: 49-56, 2013.

19. Nel I, Gauler TC, Bublitz K, Lazaridis L, Goergens A, Giebel B, Schuler M and Hoffmann AC: Circulating tumor cell composition in renal cell carcinoma. PLoS One 11: e0153018, 2016.

20. Rapposch S, Zangerl P and Ginzinger W: Influence of fluorescence of bacteria stained with acridine orange on the enumeration of microorganisms in raw milk. J Dairy Sci 83: 2753-2758, 2000

21. Houtman CJ, Kitin P, Houtman JC, Hammel KE and Hunt CG: Acridine orange indicates early oxidation of wood cell walls by fungi. PLoS One 11: e0159715, 2016.

22. Lucantoni L, Silvestrini F, Signore M, Siciliano G, Eldering M, Dechering KJ, Avery VM and Alano P: A simple and predictive phenotypic High Content Imaging assay for Plasmodium falciparum mature gametocytes to identify malaria transmission blocking compounds. Sci Rep 5: 16414, 2015.

23. Aydinlik S, Erkisa M, Cevatemre B, Sarimahmut M, Dere E, Ari F and Ulukaya E: Enhanced cytotoxic activity of doxorubicin through the inhibition of autophagy in triple negative breast cancer cell line. Biochim Biophys Acta 1861: 49-57, 2016.

24. Duan L, Danzer B, Levenson VV and Maki CG: Critical roles for nitric oxide and ERK in the completion of prosurvival autophagy in 4OHTAM-treated estrogen receptor-positive breast cancer cells. Cancer Lett 353: 290-300, 2014

25. Martens S: No ATG8s, no problem? How LC3/GABARAP proteins contribute to autophagy. J Cell Biol 2016. pii: jcb.201611116 (Epub ahead of print).

26. Citterio B, Albertini MC, Ghibelli L, Falcieri E, Battistelli M, Canonico B, Rocchi MB, Teodori L, Ciani M and Piatti E: Multiparameter analysis of apoptosis in puromycin-treated Saccharomyces cerevisiae. Arch Microbiol 197: 773-780, 2015

27. Wentland EJ, Stewart PS, Huang CT and McFeters GA: Spatial variations in growth rate within Klebsiella pneumoniae colonies and biofilm. Biotechnol Prog 12: 316-321, 1996.

28. Venkatesh S and Dada R: Acridine orange binding to RNA interferes DNA fragmentation index calculation in sperm chromatin structure assay. Fertil Steril 94: e37, author reply e38, 2010.

29. Lim LS, Hu M, Huang MC, Cheong WC, Gan AT, Looi XL, Leong SM, Koay ES and Li MH: Microsieve lab-chip device for rapid enumeration and fluorescence in situ hybridization of circulating tumor cells. Lab Chip 12: 4388-4396, 2012.

30. Levi O, Tal B, Hileli S, Shapira A, Benhar I, Grabov P and Eliaz N: Optimization of EGFR high positive cell isolation procedure by design of experiments methodology. Cytometry B Clin Cytom 88: 338-347, 2015.
31. Yusa A, Toneri M, Masuda T, Ito S, Yamamoto S, Okochi M, Kondo N, Iwata H, Yatabe Y, Ichinosawa Y, et al: Development of a new rapid isolation device for circulating tumor cells (CTCs) using 3D palladium filter and its application for genetic analysis. PLoS One 9: e88821, 2014.

32. Liu CH, Sahoo SL and Tsao MH: Acridine orange coated magnetic nanoparticles for nucleus labeling and DNA adsorption. Colloids Surf B Biointerfaces 115: 150-156, 2014

33. Rossi E, Fassan M, Aieta M, Zilio F, Celadin R, Borin M, Grassi A, Troiani L, Basso U, Barile C, et al: Dynamic changes of live/apoptotic circulating tumour cells as predictive marker of response to sunitinib in metastatic renal cancer. Br J Cancer 107: 1286-1294, 2012.

34. Tanaka F, Yoneda K, Kondo N, Hashimoto M, Takuwa T, Matsumoto S, Okumura Y, Rahman S, Tsubota N, Tsujimura T, et al: Circulating tumor cell as a diagnostic marker in primary lung cancer. Clin Cancer Res 15: 6980-6986, 2009.

35. McKiernan JM, Buttyan R, Bander NH, de la Taille A, Stifelman MD, Emanuel ER, Bagiella E, Rubin MA, Katz AE, Olsson CA and Sawczuk IS: The detection of renal carcinoma cells in the peripheral blood with an enhanced reverse transcriptase-polymerase chain reaction assay for MN/CA9. Cancer 86: 492-497, 1999.

36. Pinzani P, Mazzini C, Salvianti F, Massi D, Grifoni R, Paoletti C, Ucci F, Molinara E, Orlando C, Pazzagli $M$ and Neri B: Tyrosinase mRNA levels in the blood of uveal melanoma patients: Correlation with the number of circulating tumor cells and tumor progression. Melanoma Res 20: 303-310, 2010.

37. El-Naggar AK, Batsakis JG, Teague K, Giacco G, Guinee VF and Swanson D: Acridine orange flow cytometric analysis of renal cell carcinoma. Clinicopathologic implications of RNA content. Am J Pathol 137: 275-280, 1990.

38. Smerage JB, Barlow WE, Hortobagyi GN, Winer EP, Leyland-Jones B, Srkalovic G, Tejwani S, Schott AF, O'Rourke MA, Lew DL, et al: Circulating tumor cells and response to chemotherapy in metastatic breast cancer: SWOG S0500. J Clin Oncol 32: 3483-3489, 2014.

39. Juratli MA, Sarimollaoglu M, Nedosekin DA, Melerzanov AV, Zharov VP and Galanzha EI: Dynamic fluctuation of circulating tumor cells during cancer progression. Cancers (Basel) 6: $128-142,2014$

40. Coumans FA, Siesling S and Terstappen LW: Detection of cancer before distant metastasis. BMC Cancer 13: 283, 2013.

41. Gkountela S, Szczerba B, Donato C and Aceto N: Recent advances in the biology of human circulating tumour cells and metastasis. ESMO Open 1: e000078, 2016.

42. Hart IR: The selection and characterization of an invasive variant of the B16 melanoma. Am J Pathol 97: 587-600, 1979.

43. Liotta LA, Kleinerman J and Saidel GM: Quantitative relationships of intravascular tumor cells, tumor vessels, and pulmonary metastases following tumor implantation. Cancer Res 34: 997-1004, 1974.

44. Smith SJ, Wilson M, Ward JH, Rahman CV, Peet AC, Macarthur DC, Rose FR, Grundy RG and Rahman R: Recapitulation of tumor heterogeneity and molecular signatures in a 3D brain cancer model with decreased sensitivity to histone deacetylase inhibition. PLoS One 7: e52335, 2012.

45. Fidler IJ: Biological heterogeneity of cancer: Implication to therapy. Hum Vaccin Immunother 8: 1141-1142, 2012.

46. Zhou J, Huang A and Yang XR: Liquid Biopsy and its potential for management of hepatocellular carcinoma. J Gastrointest Cancer 47: 157-167, 2016. 